\title{
First Degree Family History of Esophageal or Gastric Esophageal Cancer
}

National Cancer Institute

\section{Source}

National Cancer Institute. First Degree Family History of Esophageal or Gastric

Esophageal Cancer. NCl Thesaurus. Code C157439.

Parents, siblings or children of an individual have a history of esophageal or gastric esophageal cancer. 